\title{
The Sense of Place: Components and Walkability. Old and New Developments in Dubai, UAE
}

\author{
Maryam Marzbani \\ Islamic Azad University, Iran \\ m.marzbani@iau.ae \\ Jihad Awad \\ Ajman University, United Arab Emirates \\ j.awad@ajman.ac.ae
}

\author{
Mahmud Rezaei \\ Islamic Azad University, Iran \\ m.rezaei@iauctb.ac.ir
}

\begin{abstract}
This research attempts to address the question "which of the "physical", "social" or "perceptual" aspects of a place has had a more significant impact on walkability?" The main goals were to identify, quantify, and compare the tangible (physical) and less tangible (perceptual, social) aspects of urban walkability as well as how they impact urban walkability in the new versus traditional developments in Dubai. The significance of this research lies in higher weight it places on the quantitative rather than merely the qualitative features of walkability, in order to provide more practical guidelines and measurements. This emphasis reflects a gap in the literature on walkability which is focused more on the latter than the former. Planners, public and city officials can use these findings in their decisions. The findings indicate that the sense of place in the historical fabric of Bastakiyah (old part of Dubai) is totally higher than the new development of Jumeirah Beach Residence (JBR). But it has more been the physical aspect, rather than lesstangible factors of the place, in both cases, that normally has improved the whole sense of the place felt by visitors, inhabitants and users. Yet, the behavioural and perceptual criteria need to be improved, in comparison with the mere physical attractions, in order to create a more balanced place for walkability in Dubai. In this study, the combinations of qualitative and quantitative methods have been used. Urban dimensions and their effects on walkability have been qualitatively identified and categorized through administering a survey questionnaire. These dimensions were then measured in Dubai. Lastly, the collected data have been statistically analysed and described with the SPSS program.
\end{abstract}

Keywords: walkability, sense of place, urban design, Dubai

To cite this article:

Marzbani, M., Awad, J., Rezaei, M. (2020). The Sense of Place: Components and Walkability. Old and New Developments in Dubai, UAE, The Journal of Public Space, 5(I), 21-36, DOI

10.3289I/jps.v5il.1249

This article has been double blind peer reviewed and accepted for publication in The Journal of Public Space. 


\section{Introduction}

In the wake of the industrial revolution, urban population exploded and cities expanded. The rush of new developments in urban areas, the auto industry, and the priority given to cars rather than human forced a pattern shift from walking to driving. The standards of the built environment transformed in a way that cities became un-walkable for people from all walks of life.

It goes without saying that the promotion of walking behaviour would reduce the individual, social, environmental, and economic problems related to physical and mental illnesses, traffic congestion, environmental injustice, social isolation and rising health care costs (Forsyth, 2015) (Speck, 2012) (Lehman, 2007) (Lee, 2008) (Pucher, 2003). Several studies and research have distinguished level of walkability relates to a wide range of influences such as the physical condition of the place, social behaviour, socioeconomic factors, and sense of a place. However, from the viewpoint of architects and planners, walkability holds a meaningful relationship with the conditions of the built environment and the sense of place (Forsyth, 2015) (Joh, 20II) (Rezaei, 20I4) (Adkins, 2017). The sense of place has three main components namely "physical", "perceptual" and "behavioural" (Lynch, 1960) (Montgomery, 1998) (Carmona, 2006). Over the past few decades, a wide range of walkability definitions and frameworks have been introduced in the literature. While some concentrate on the physical conditions of the road, others link it to the individual characteristics. There are also a few proposed frameworks that have a holistic approach while considering more effective factors (Forsyth, 20I5) (Yang, 20I6) (Marzbani, 20I4).

Although, in recent years, enhancing the walkability of communities has become a key concern in many fields such as urban planning, geography, and psychology, still our knowledge of what makes walking a zero-pollution means of travel, a preference for residents is quite limited. Most of the related studies are qualitative rather than quantitative. Besides, one barely sees an integrated walkability research based on every aspect of a place. The two paths compared in this study are located in Dubai, which is a sample of a modern sprawl development and heavily car-dependent city. Recently, the UAE's government has made considerable efforts to make Dubai a walkable city so as in order to reduce the range of issues affecting its residents including diabetes, obesity, unhappiness, traffic congestion and the like.

Qualitative and quantitative methods have been used to review the role of each element of sense of a place in increasing walkability. The first stage was based on observation, data collection and the qualitative analysis of the data, and conducting a survey using Delphi method. In the second phase, the collected data were analysed by a software called Statistical Package for the Social Sciences (SPSS). The significance of this study is in quantifying the aspects of "sense of place", measuring and comparing the level of their influence on walkability from the viewpoint of the various professionals. The conclusions could be applied by master planners, municipalities, urban planning councils, and consulting firms for future projects.

The findings of this research indicated that the walkability of the two studied paths, one in historical fabric and one in new development of Dubai, is approximately in the same level. Additionally, it showed that of the three main components of a place, the physical aspects have the major role in enhancing walkability. The perceptual aspects come in 
second place followed by the behavioural aspects. The research highlights the necessity to pay more attention to the social and perceptual aspects of design in Dubai. In the following, the different aspects of sense of place and their relationship with walkability in the existing literature will be reviewed which is followed by the case studies. Lastly, the findings will be discussed and determined the role of each component of urban dimension in order to increase the walkability in Dubai.

\section{Walkability and Sense of Place}

The history of modern cities developments demonstrates two major trends or 'movements' that have emerged since the time of the industrial revolution. The first, industrial revolution itself and the second trend in urban design took full hold in the post-war era, with the rise of the suburbs. In a sense, the suburbs represent a continuation and intensification of the compartmentalization movement, as the living areas of the upper classes were separated-off still further from the other areas of the city-out into sprawling districts miles away (as automobiles made it possible for certain city dwellers to escape to an idealized haven away from the hustle and bustle) (Montgomery, 20I3). The seductive power of suburbanization accelerated in the late nineteenth century as the industrial revolution made cities larger and more machinelike. At the same time, the growing middle class could now afford to move from older urban neighbourhoods to new homes in naturalistic settings on the outskirts. From the industrial city arose not just a desire to escape but a desire to experience a convivial "village life" with its image of a more human scale and tightly knit sense of community (Fulton, 1997). For example, the City Beautiful movement borrowed heavily from France's Beaux Arts school of architecture. With its emphasis on civic buildings, plazas and landscaped parks, this movement sought, in the words of Todd Bressi, to "impose a sense of order, civility and purpose on chaotic industrial cities (Bressi, 1994). The Garden City movement is another movement emerging out of the new profession of city planning at the turn of the century also sought to create a "sense of place" and restore the notion of village life to modern urban development. But this Garden City movement was less formalistic, more oriented toward "green" natural areas, parks and walkways that safely isolated neighbourhood activity from the street (Fulton, 1997). Walkability studies and observation of different built environment demonstrate a strong relationship between "sense of place" and "walkability". However, in various fields of study, both concepts have been defined in different ways.

Some discussions of walkability focus on the means or conditions by which walking is enabled, including areas being traversable, compact, physically-enticing, or safe. Others propose that walkability is about the outcomes or performance of such walkable environments, such as making places lively and sociable, enhancing transportation options, or inducing exercise. A final set of discussions uses the term walkability as a proxy for better urban places-with some paying attention to walkability being multidimensional and measurable and others proposing that enhancing walkability provides a holistic solution to a variety of urban problems (Speck, 20I2) (Rezaei, 20I4). Furthermore, of all the built environment theories, the holistic module is the most complete one. It argues that any given place cannot be recognized unless all three of its main aspects, namely "physical”, "social”, and "perceptual”, have been well-defined. 
"An environmental image may be analysed into three components: identity, structure, and meaning" (Carmona, 2006). "We should remember what make a city is not just physical, social aspects, but a perceptual aspect of place and the relation of these three aspects of place together" (Carmona, 2006).

The following by Punter and Montgomery (Carmona, 2006) illustrate the relationships between a place with its components.

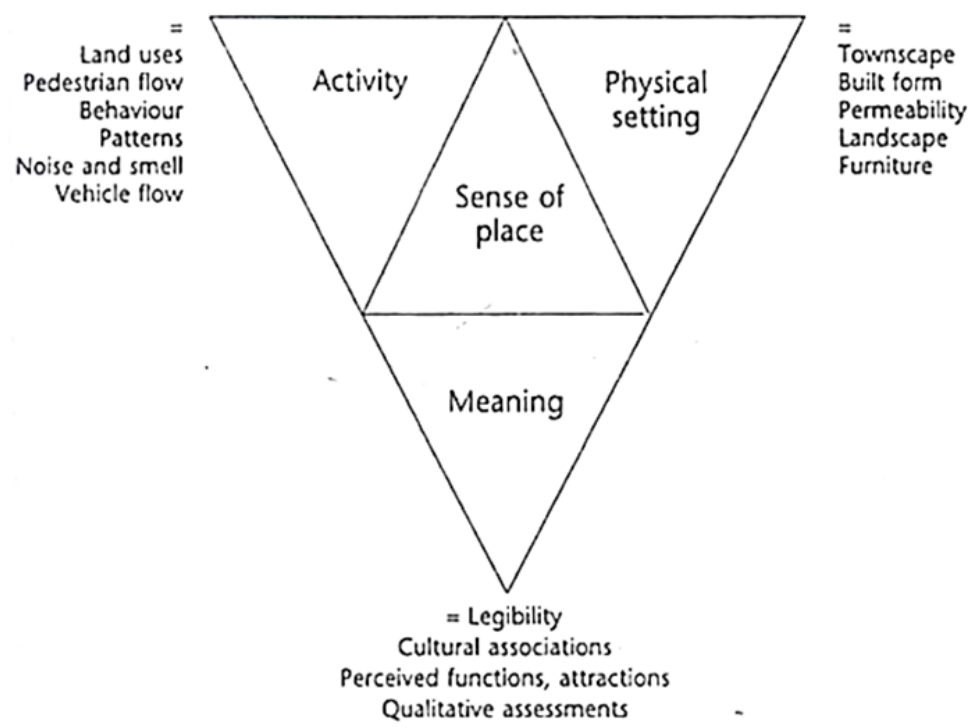

Figure I. Diagram of Sense of Place by Punter and Montgomery. Source: Carmona, 2006, p. 99.

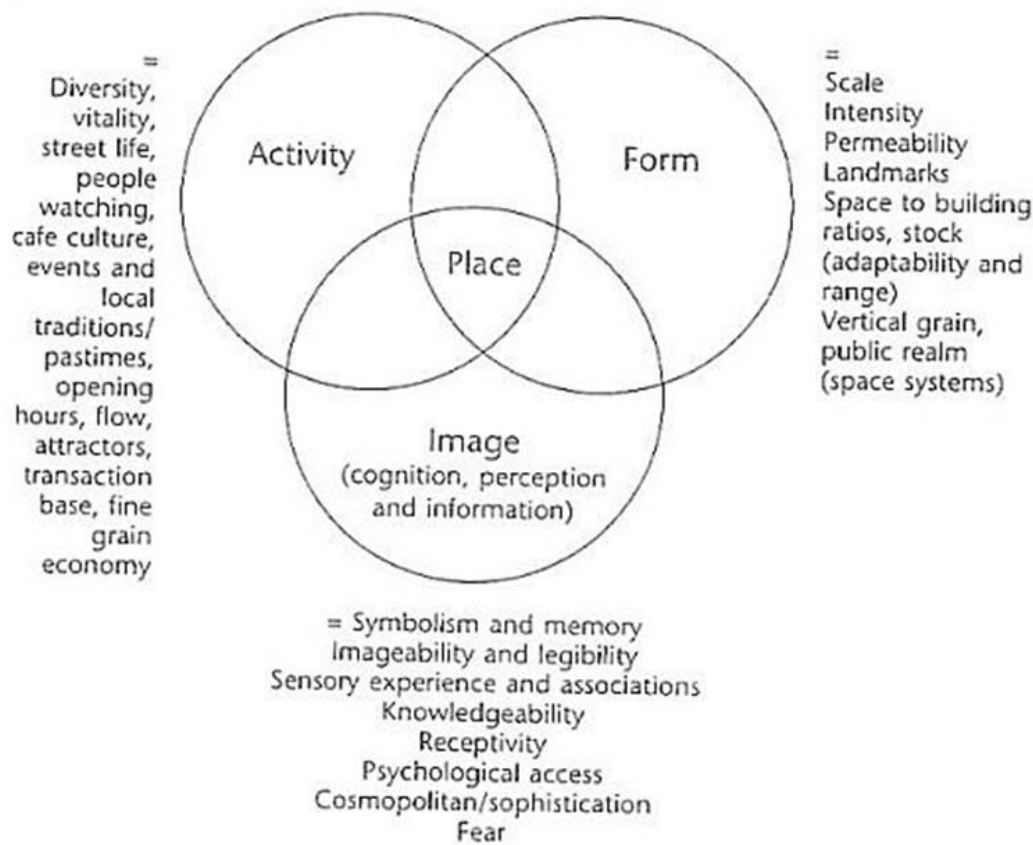

Figure 2. The Components of Place. Source: Montgomery, 1998. 
Although, there are many different methods and approaches to decide whether a place is walkable or not, this study follows the models suggested by Lynch, Punter and Montgomery, and includes "Physical Features", "Social Activities", and "Perceptual Dimensions".

\section{Physical Features}

Over the course of time, physical characteristics of a place were the main concern of architects and designers. Therefore, the major urban theories of walkability include some features of the built environment in certain levels. In this respect, the five physical dimension of a place has been derived from Carmona module of eight subcategories namely: ecological, spatial, morphology, contextual, and visual. The Carmona module includes three more urban dimension of social, functional, and perceptual which are not under physical subcategory of a place (Carmona, 200I). In the next few paragraphs the key concepts of each physical aspect associated with walkability will be presented.

The Ecological Aspects of a place that are in accordance with walkability in the urban literature are sustainable design, ecology, energy efficiency, orientation, sunlight, green areas and trees, microclimate, natural specifications, waterfronts, shade and shadow, and topography (Rogers, 1977) (Coupland, 1996) (Bacon, 1967) (Blowers, 1993).

The Spatial Aspects are the dimensions of a place that highly affect the human behaviour which are compact or sprawl form of built environment, mixed-used, open spaces, road hierarchy, settlement pattern, neighbourhoods, mobility, hierarchy level of public and private, permeability of the space, scales, range of vehicle-users, availability of pubic transportations, structure of the space, accessibility and built up density (Garreau, 199I) (Calthorpe, 1993) (Fery, 1999) (Lynch K. , 1980) (Hough, 1990).

The Morphology Aspects are one of those important factors that have major impacts on the human behaviour. Historically, architects have sought to understand and identify patterns of built environment, housing, crosswalk, side parking, building lines, density (figure and ground), layout, public spaces, street pattern, plazas and squares, block size, connectivity, edges, grain, design, nodes, landmarks, network, proportion, and building materials (Sitte, 1889) (Alexander, 1977).

The Contextual Aspects of any place have a strong influence on its identity. Surrounding context, harmony, building arrangements, building functions, connectivity, corners, conservation, height, neighbourhood impact, landscape, views, vistas, religious contexts, traditional design, outlook, boundaries, and building groups are some components of the contextual aspects affecting the level of walkability (Tibbalds, 1992) (Worskett, 1969) (Nairn, 1956).

The Visual Aspects link to walkability of a place are the art of giving coherence, organization, views to and from, visual amenities, transparency, mass, colour, styles, materials, scale, texture, detailed, balance, corners, focal points, forms, harmony, land marks, proportion, rhythm, roofs cape, skyline, solid v. bulk void, vertical v. horizontal, visibility and hide of the urban utilities, parking areas, night visions, and visual connectivity for the pedestrians (Cullen, 196I) (Gibberd, 1967) (Unwin, 1909). 


\section{Social Activities}

"Towns and cities are more than just collections of buildings crisscrossed by roads and augmented by the occasional park. They are essentially for and about people. They accommodate their activities. The more well-used and varied they are, the more they are likely to have the quality of people friendliness" (Tibbalds, 1992).

Outdoor activities are influenced by a number of physical and perceptual factors. On this subject, Jan Gehl categorized these activities into three types. According to her the three categories of outdoor activities are:" Necessary", "Optional", and "Social". "Outdoor activities in public spaces can be divided into three categories, each of which places very different demand on physical environment: necessary activities, optional activities and social activities. .... When outdoor areas are of poor quality, only strictly necessary activities occur" (Gehl, 1987).

The Necessary Activities include those that are more or less mandatory, such as going to work or waiting for a bus. The frequency of these activities is influenced only slightly by the physical conditions. However, infrastructures, access, active frontages, crime, disable access, patterns of movement, public realm, public health, public space, social equality, social cohesion, minority needs, personalization, security, gender, age and race possibly increase or decrease the level of necessary activities (Jacobs, 196I) (Bently, 1985) (Whyte, 1980) (Newman, 1973).

The Optional Activities are willingly-done behaviours. This category includes such activities as taking a walk to breath in fresh air or standing around and enjoying life. These activities take place only when physical and perceptual situations are suitable. Physical conditions are highly important in forming this category of behaviour. The elements that greatly affect the optional activities are greater efficiency of space, freedom for walking, facilities for eat, seat, stand, pedestrians, crossing, feel safe at night, third place, play space, comfort, security, safety, vitality, number and variety of people, cleanliness, privacy, and personalization, to name a few (Buchanan, 1988) (Lang, 1994).

The Social Activities are those events that depend on the presence of others in the public spaces such as greetings and conversations or even passive contacts that is, simply seeing and overhearing other people. Social activities are ultimately formed when necessary and optional activities are given better conditions. They also depend on the presence of physical and perceptual aspects. Providing entertaining amenities and facilities, safety, mixed-used, green area, lighting, traffic calming, crossways, public services, and shadows can be mentioned under this heading (Buchanan, 1988) (Lang, 1994) (Cooper, 1988).

\section{Perceptual Dimensions}

The diverse and sometimes conflicting responses of people to certain environments point out the importance of consideration of perceptual aspects in planning and design of the built environment.

"Environment perception is the human awareness and understanding of environment in general sense" (Kopec, 20I2). 
According to Kopec (2012) the process of understanding environment or our sense of place is formed in two main phases, namely "Perception" and "Cognition".

The Perception Phase or the temporal dimension of a place mainly refers to the processing of understanding the sensual experience. Sensation refers to the simple biological experience elicited by the environment, includes sounds, smells, touches, views, the sights and aesthetic perceptions, image ability, cultural background of people, flexibility of the place, development and renewal, visual reminder of past use, form and expression of current change are the terms in relations with the temporal aspects (Bacon, 1967) (Kopec, 2012) (Hough, 1990) (Xu, 1995).

"Perception, the first phase in overall thought process, involves in interpretation of sensations" (Kopec, 20I2).

The Cognition Phase or mental dimension of a place is the understanding that derives out from process of perception phase, and then leads to cognitive thought, which is based on reminder (Banich, 2004).

Cognition, the second phase, is the way that information and knowledge comes to be known, through the actions of perception, reasoning or intuition. Cognition is the way in which we think, learn, from memories, and make decisions.

Lynch's five elements (paths, edges, districts, nodes, and landmarks), civic pride, distinctiveness, enclosure, sense of belonging, variety, human scale, identity and uniqueness, image, memorial perception, legibility, finding the way, are other terms related to mental dimension of a place (Kopec, 2012) (Appleyard, 198I) (Rapoport, 1982) (Shahcheraghi, 2015).

Above is a list of different elements identifying a place and its relationship with walkability. It is possible to create a hierarchy list as the physical aspects are the precondition for the social activities, and the two as tangible elements of a place enhance or ruin the perception of people about a place over time.

\section{Is Dubai a Walkable City?}

Even though the vision for the UAE is to reduce auto dependency, "Dubai ranks among the highest car-oriented cities with 550 vehicles per 1000 residence" (Happy City, 20 I7). As of today, this city is not walkable due to the following reasons: urban sprawl, lack of public transportation, the roads which are being designed in favour of cars, lack of shadows, harsh weather, lack of sidewalks in many places, and the socio-economic factors.

"One of the first impressions of the city is its fragmentary nature and the reliance on cars as the primary means of circulation. Dubai is composed of multiple, disconnected centres, which are separated by multi-line highways"

(Elsheshtawy, 20I3).

"We are carrying out both strategic and detailed measures to reduce auto dependency and alleviate traffic volume. On the strategic level, Dubai 2020's master plan promotes a transit-oriented development policy aimed at concentrating business and population around Dubai metro stations to increase ridership"

(Serkal, 2016). 


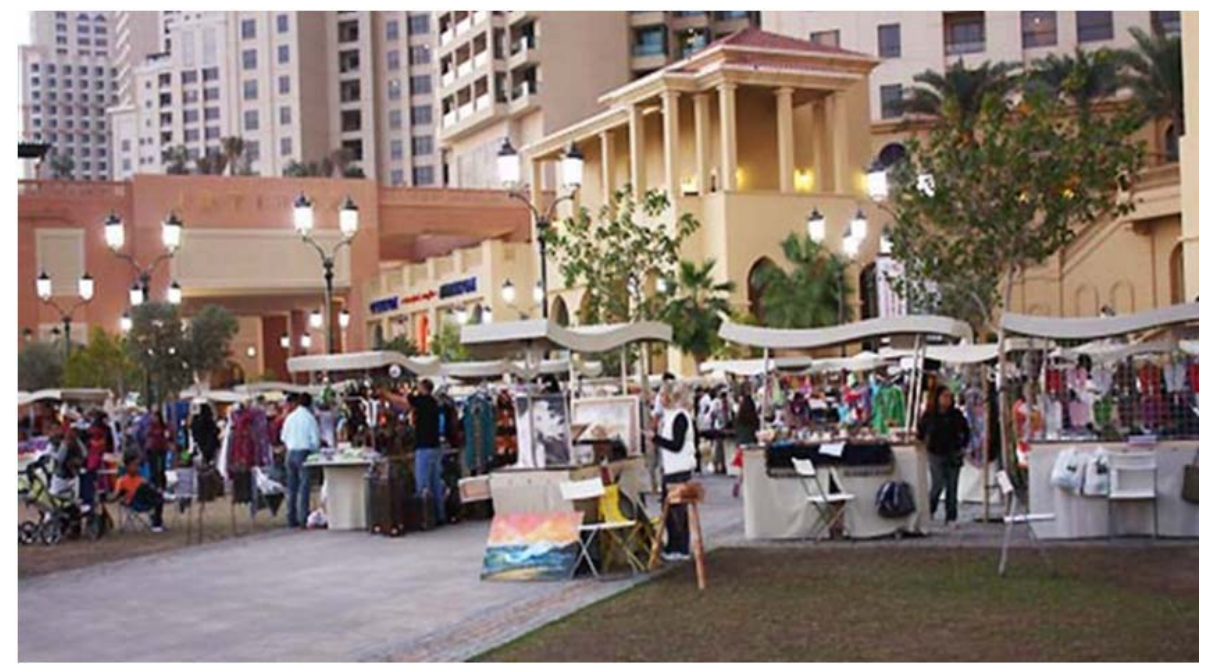

Figure 3. Jumairah Beach Residence (JBR), Source: Authors.

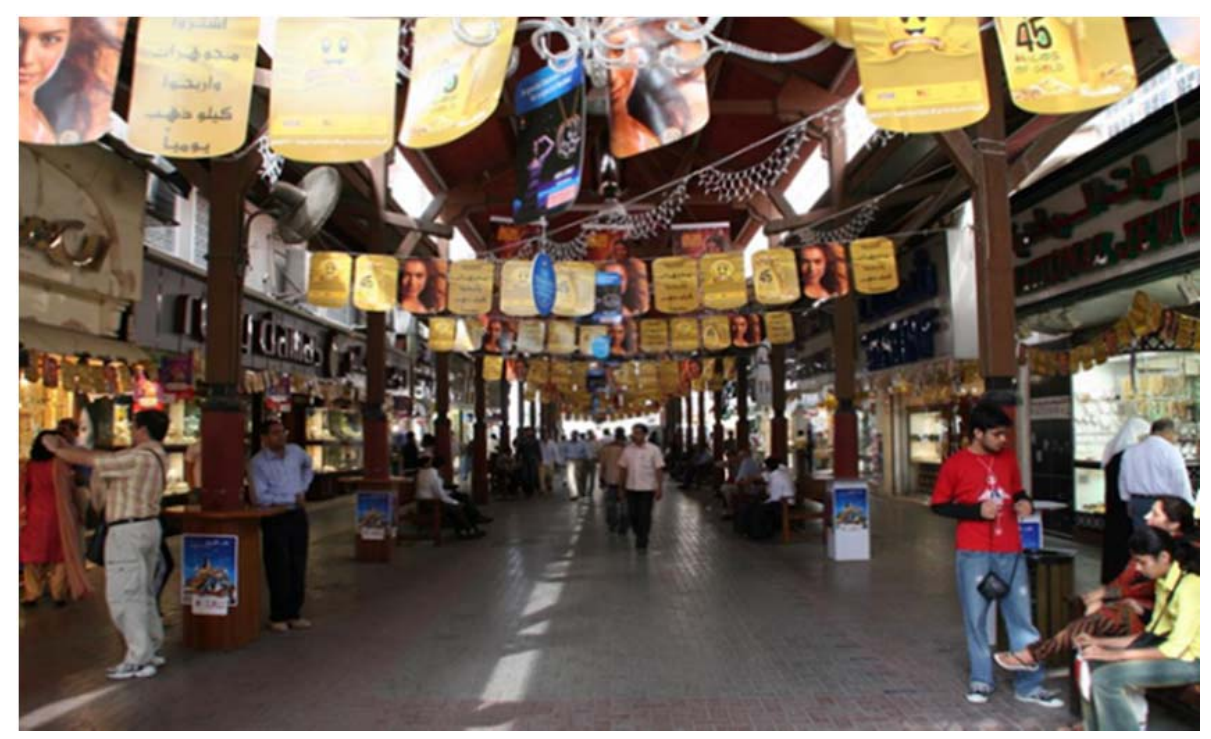

Figure 4. Souq al Kabeer in Bastakiyah, Source: Authors.

Dubai is becoming more walkable, several well designed successful recent projects like "Jumairah Beach Residence (JBR)","The Sustainable City”, "The City Walk”, "The Box Park", "La Mer", provided more space for people to walk. Some physical conditions like hot and humid weather of Dubai is a challenge and hits the level of comfort during summer, it has ease temperature during at least more than half of the year. While the historical fabric of Dubai has been formed with respect to the human scale and the local culture and climate, the new developments have been designed in a rush to accommodate population explosions and car requirements. Jumeirah Beach Residence (JBR) is the first place in the new development of Dubai which can be termed as walkable. Dubai's actual downtown and historical fabrics (Bur Dubai and Deira) are easy to walk. In this research, the walkability of a historical part of Dubai, called Bastakia and the new development of Jumeirah Beach Residence will be reviewed and compared. 


\section{Methodology}

According to Speck (2012) generally downtowns are more capable for walking compared to the new developments. Hypothesis of this study was the sense of historical fabric in Dubai has a significant impact on enhancing walkability. To compare the level of the walkability of paths, a number of studies have been done; however, most of them were merely qualitative studies. Also, how different aspects of the sense of place influence the walkability has been under quantified. In this research, a combination of quantitative and qualitative approaches (mixed method) has been used to find out the role of each urban element in boosting the walkability in Dubai.

Initially, observations acknowledge that the number of walkers in historical fabrics of Dubai is not more than that of new developments. By reviewing several mainstream urban theories and frameworks including new urbanism, sustainable developments, smart growth, TOD, and so on the literature of sense of place and walkability has been documented and categorized (Marzbani, 20I4). Then, an integrated questionnaire' was administered in order to measure the role of each aspect of the sense of place on walkability from the viewpoint of 23 architects and urban planners (all professionals who live or used to live in the UAE, and were very familiar with both paths). Analysing the questionnaire required statistical analysing; therefore, its outcomes have been analysed with "Statistical Package for the Social Sciences (SPSS) program".

Although prior researches aimed to recognize the most important factors affecting the level of walkability of a place, it remains unclear why some places are more walkable than others. Indeed, a holistic measurable study is required to understand the roles of all tangible and intangible factors.

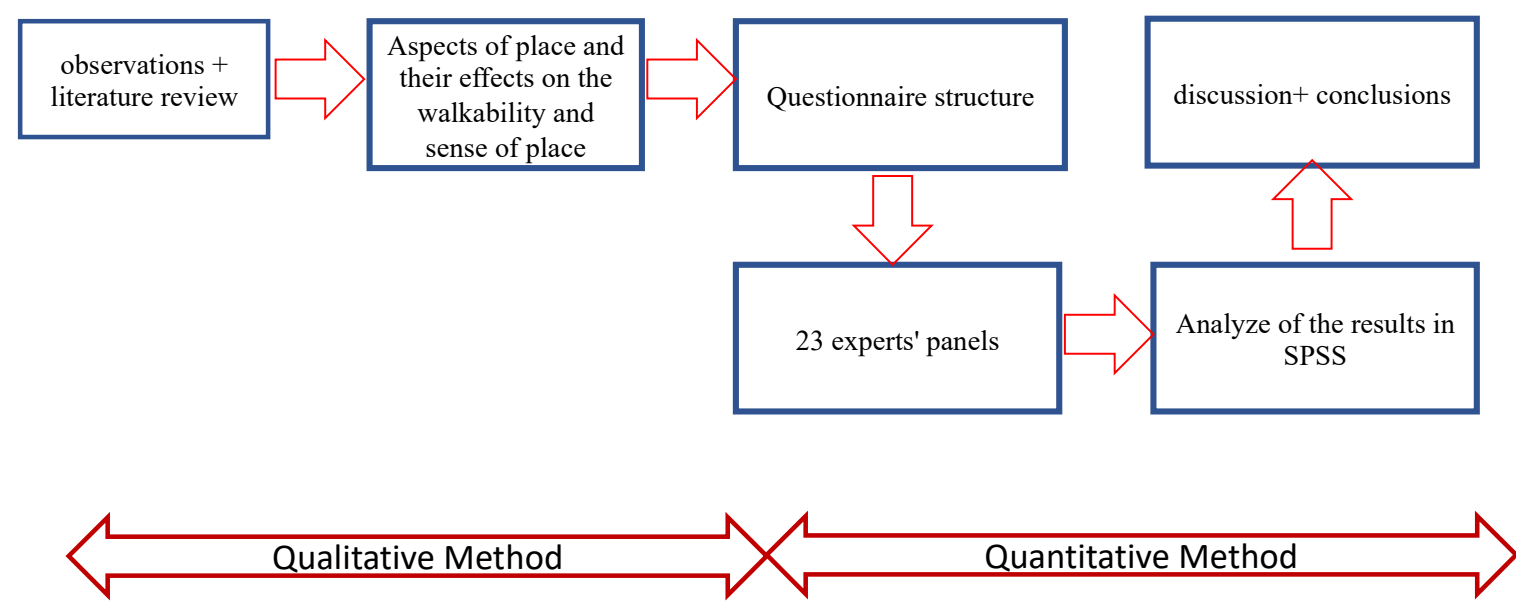

Diagram I. Illustration of Methodology

\footnotetext{
I This research and the related questionnaire have been designed to focus on place, thus other factors like economic or political influences on walkability have not been highlighted.

${ }^{2}$ SPSS is a data management and analysis product.
} 


\section{Results and Findings}

Tables I to 6 demonstrate the valuation of the physical, social, and perceptual aspects in the historical fabric of Bastakiyah and the new development of JBR based on outcomes derived from the questionnaire. Table I shows that the physical aspects of historical fabric are on an average level. About $9.5 \%$ of interviewees evaluated this aspect at a low level, $61 \%$ at a normal level and the remaining $28.6 \%$ evaluated at a high level. In mean time, Table 2 indicates in the new development, $4.5 \%$ percent believed it to be in poor conditions, $52.2 \%$ in fair conditions, and $39.1 \%$ evaluated it as good. Indeed, the overall physical condition in the JBR is higher to that of the historical fabric.

\begin{tabular}{|c|c|c|c|}
\hline $\begin{array}{c}\text { Physical } \\
\text { Bastakiyah }\end{array}$ & Frequency & Percentage & $\begin{array}{c}\text { Valid } \\
\text { Percentage }\end{array}$ \\
\hline Poor & 2 & 8.7 & 9.5 \\
\hline Fair & 13 & 56.6 & 61 \\
Good & 6 & 26.1 & 28.6 \\
\hline Total & 21 & 100.0 & 99.1 \\
\hline
\end{tabular}

Table I. Valuation of Physical Aspects in Bastakiyah

\begin{tabular}{|c|c|c|c|}
\hline $\begin{array}{c}\text { Behavioral } \\
\text { Bastakiyah }\end{array}$ & Frequency & Percentage & $\begin{array}{c}\text { Valid } \\
\text { Percentage }\end{array}$ \\
\hline Poor & 6 & 26.1 & 26.1 \\
\hline Fair & 11 & 47.8 & 47.8 \\
\hline Good & 6 & 26.1 & 26.1 \\
\hline Total & 23 & 100.0 & 100.0 \\
\hline
\end{tabular}

Table 3. Valuation of Behavioral Aspects in Bastakiyah

\begin{tabular}{|c|c|c|c|}
\hline $\begin{array}{c}\text { Perceptual } \\
\text { Bastakiyah }\end{array}$ & Frequency & Percentage & $\begin{array}{c}\text { Valid } \\
\text { percentage }\end{array}$ \\
\hline Poor & I & 4.3 & 4.5 \\
\hline Fair & 10 & 39.1 & 40.9 \\
\hline Good & 11 & 47.8 & 50.0 \\
\hline Total & 22 & 100.0 & 95.4 \\
\hline
\end{tabular}

Table 5. Valuation of Perceptual Aspects in Bastakiyah

\begin{tabular}{|c|c|c|c|}
\hline Physical JBR & Frequency & Percentage & $\begin{array}{c}\text { Valid } \\
\text { Percentage }\end{array}$ \\
\hline Poor & 1 & 4.3 & 4.5 \\
\hline Fair & 12 & 52.2 & 52.3 \\
Good & 9 & 39.1 & 40.9 \\
\hline Total & 22 & 100.0 & 97.7 \\
\hline
\end{tabular}

Table 2. Valuation of Physical Aspects in JBR

\begin{tabular}{|c|c|c|c|}
\hline Behavioral JBR & Frequency & Percentage & $\begin{array}{c}\text { Valid } \\
\text { Percentage }\end{array}$ \\
\hline $\begin{array}{c}\text { Poor } \\
\text { Fair }\end{array}$ & 1 & 4.3 & 4.3 \\
\hline Good & 14 & 34.8 & 34.8 \\
\hline Total & 23 & 100.0 & 60.9 \\
\hline
\end{tabular}

Table 4. Valuation of Behavioral Aspects in JBR

\begin{tabular}{|c|c|c|c|}
$\begin{array}{c}\text { Perceptual } \\
\text { JBR }\end{array}$ & Frequency & Percentage & $\begin{array}{c}\text { Valid } \\
\text { Percentage }\end{array}$ \\
\hline Poor & 1 & 4.3 & 4.3 \\
\hline Fair & 13 & 56.5 & 56.5 \\
Good & 9 & 39.1 & 39.1 \\
Total & 23 & 100.0 & 99.9 \\
\hline
\end{tabular}

Table 6. Valuation of Perceptual Aspects in JBR 
Data from the Table 3 depicts that 26.1 percent of the interviewees believed the role of the behavioural aspects in the studied historical fabric was in a low level, 47.8 percent see them fair and 26.I percent evaluated them as good. Table 4 indicates behavioural aspect of new development; 4.3 percent in poor, 34.8 percent fair, and 60.9 percent good. Accordingly, Tables 3 and 4 illustrate that behavioural aspects have the better situation in JBR.

Table 5 represents the percentage of the perceptual indicator in the historical fabric. Based on that about $4.5 \%$ of the interviewees have been on the belief that perceptual aspects are poor, $40.9 \%$ evaluated it as fair, and half of them saw it as good. Finally, the data in Table 6 shows the index of perceptual aspects in the path in the new development of JBR; $4.3 \%$ of the interviewees believed they are poor, $56.5 \%$ rated them as fair and $39.1 \%$ marked them good. So the indicators of the perceptual aspects in the historical fabric of Bastakiyah are stronger than the new development path of JBR. Table 7 demonstrates the relationship between independent and dependent variables and displays the correlation rate. The Coefficient Pearson of physical aspects is $0.4 \mathrm{I} 2$, for the behavioural is 0.189 and for perceptual aspects is 0.312 out of full amount (i.e. one). The most powerful relation between any indicator and walkability occurs between physical aspects of the sense of place and walkability. Followed by perceptual aspects and finally the behavioural aspects have the weakest relation with walkability in the two paths in Dubai.

\begin{tabular}{|l|l|l|l|l|}
\hline \multicolumn{2}{|l|}{ The Amount of Correlation Variables } & $\begin{array}{l}\text { Perceptual } \\
\text { Aspects }\end{array}$ & $\begin{array}{l}\text { Behavioural } \\
\text { Aspects }\end{array}$ & Physical Aspects \\
\hline \multirow{3}{*}{$\begin{array}{l}\text { Sense of Place and } \\
\text { Walkability }\end{array}$} & The coefficient Pearson & 0.312 & 0.189 & 0.412 \\
\cline { 2 - 5 } & $\begin{array}{l}\text { Significantly } \\
\text { (double-sided) }\end{array}$ & 0.002 & 0.003 & 0.000 \\
\cline { 2 - 5 } & $\mathrm{N}$ & 22 & 23 & 21 \\
\hline
\end{tabular}

Table 7. The relationship between the independent and dependent variables

All aspects of sense of place have direct effect on the walkability; moreover each component which includes physical, behavioural and perceptual features indirectly influences one other element. The relationship has been illustrated in diagram 2 . The physical aspects as most significant feature can improve both the behavioural and perceptual aspects by II and 19 percent respectively. The perceptual aspects can improve behavioural aspects with 10 percent, however it cannot change the physical conditions. The behavioural aspects do not influence neither physical nor perceptual aspects but influence by the other two characteristics. 


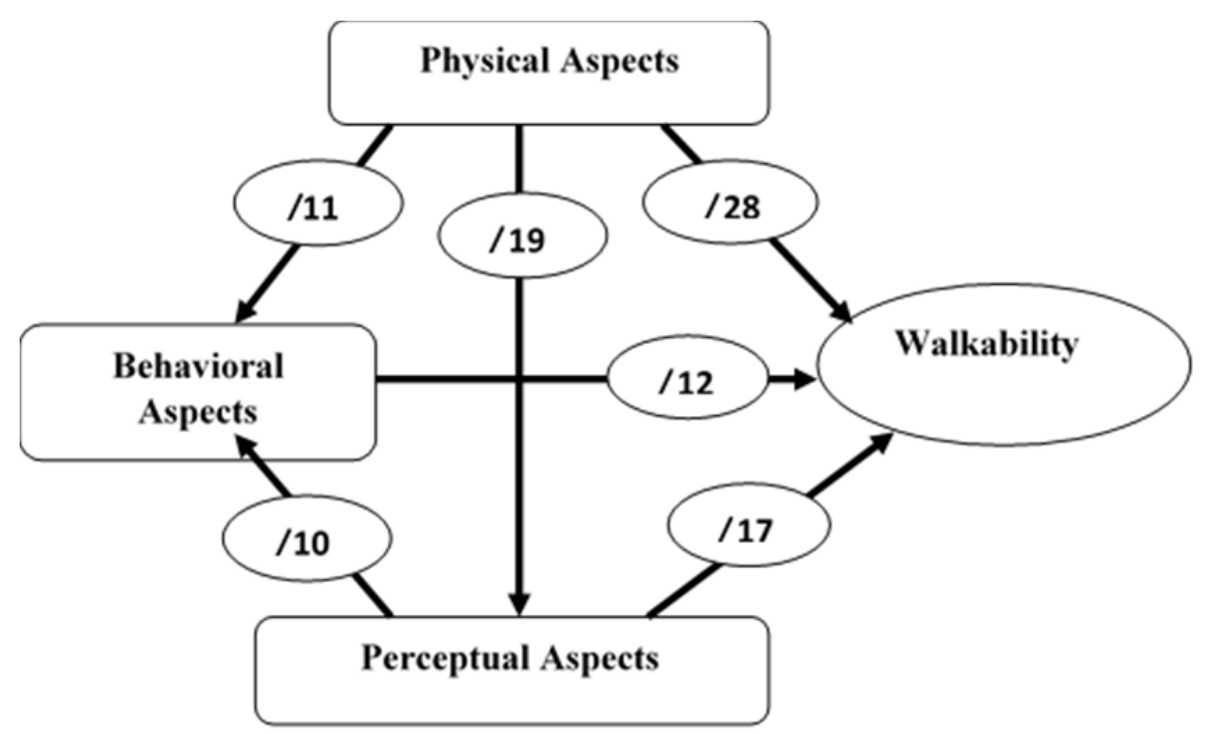

Diagram 2. Impact level of each aspect on walkability and on other aspects.

\section{Discussion}

A questionnaire has been conducted in 13 Pages for evaluating the "existing pedestrian sidewalks of Dubai". Furthermore, it was designed to compare the level of walkability in "Historical Fabric of the old Souk" (which is located in Bur Dubai between historical area of Bastakiyah and Shandaghah) with the new developments of "Jumeirah Beach Residence (JBR)" of Dubai in respect to the viewpoint of professions. In all questions the passage and sidewalks would be evaluated from I to 5 (I Very Good, 2 Good, 3 Fair, 4 Poor, and 5 Very Poor).

According to the questionnaire, $97 \%$ of the interviewed experts have confirmed that there is a relationship between the sense of the place and walkability. In Dubai, the physical aspects with a total of $58 \%$ are the most significant factors that influence the level of walkability. Perceptual aspects are the second most important factors with the total of 27 percent, and finally the behavioural aspects with I $2 \%$ indicate a weak relationship between the behavioural aspects and walkability.

Direct influences happened when the presence of some elements, like shadow or sidewalks, directly increase or decrease the number of walking individuals. Indirect impacts happened when changes in the conditions of some aspects affect in other aspects which in turn affect the level of walkability. For instance, sense of belonging, which is under perceptual category, leads to more social activities, which is under behavioural classification, which finally impact the level of walkability.

With respect to the direct influences of different aspects on walkability, physical aspects with $28 \%$ are the main factors, while the perceptual aspects have $17 \%$, and the social activities have $12 \%$ which have the least influences on the level of walkability. Regarding the indirect impacts, again the physical aspects are the most important factors with the $19 \%$ influence on perceptual aspects and II\% on the social aspects, then perceptual dimensions with $10 \%$ influence on the perceptual aspects are in the second place. Based on the outcomes, social aspects do not have any impact on the other two aspects. 
Diagram 3 illustrates the direct and indirect role of each element on walkability and sense of place.

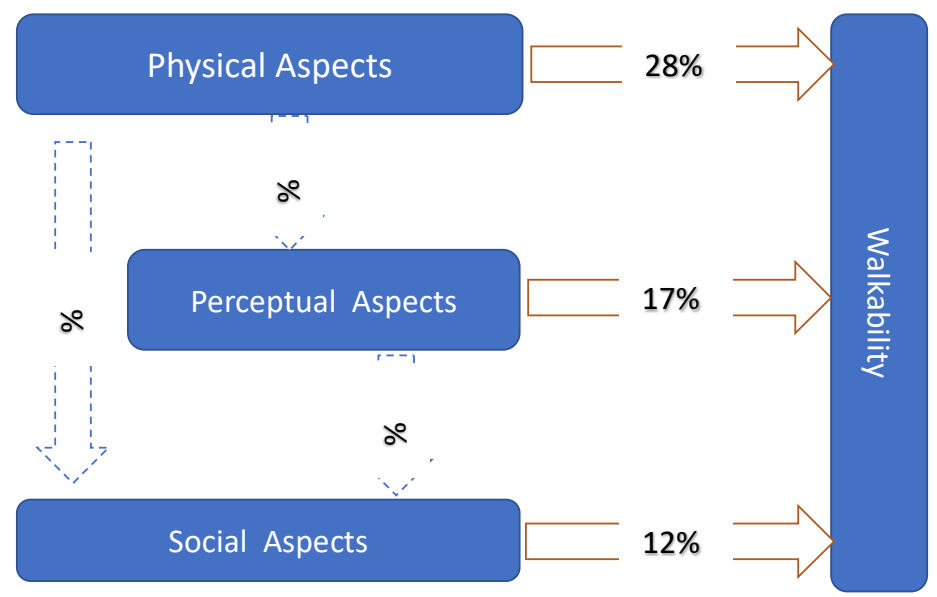

Percentage of Direct effect on Walkability

Percentage of Effect on other Aspects

Diagram 3. Direct and Indirect influence on Walkability.

The results of this research demonstrate that the physical elements of planning in Dubai have been given more attention and have been successful in achieving concrete requirements of walkability, while the social activities and the perceptual aspects have not been noticed as much. This study argues that the physical aspects of place are crucial for a place to be walkable, yet, they are not enough. The social and perceptual aspects need to be considered more in planning walkable neighbourhoods for the reason that walkability is a dynamic quality of a place and highly affects the tangible and less tangible dimensions of a place.

This research is a place-based study; indeed, other affective factors impact on level of walkability such as economy and culture, have not been included in this research.

\section{Conclusion}

Recently, automobile dominance has been a pain to individuals and social life worldwide. Getting out of cars for a walk adds to sense of a place and quality of life. Therefore, recognition, quantification, and examination of different aspects of urban dimensions and their roles in improving urban walkability is an essential requirement for creating healthy, happy communities.

Adopting a mixed-method methodology in this research was an advantage. Qualitative method used to identify the most important factors of the place which influence human 
behaviour in paths then based on outcome from a questionnaire, qualitative method eased measuring and analysing the outcomes of the survey. The framework used here and outcomes can assist architects, urban planners and decision makers to provide paths which can fulfil pedestrian needs.

Based on interviewees' evaluations, the number of pedestrians in Dubai's downtown is not more than number of walkers in the new developments. Professionals and experts who responded to this survey assert the lack of sufficient attention to social and perceptual aspects of the paths in Dubai. While the historical fabric of Bastakiah lost its original residents and its function changed, the highly physically designed JBR became an attractive place for both residents and tourists.

The finding emphasizes the importance of holistic approach in enhancing walking behaviour. In that, improving physical conditions of paths in historical areas, beside more attention to social and perceptual dimensions of place, will encourage more individuals to opt for more walk. Generally speaking, a balanced quality between physical, behavioural and perceptual conditions of any place will deliver more satisfaction and richness to the community and will invite more people to take part in the public spaces.

The method, framework and results of this research are applicable for other paths and can be beneficial for policymakers and urban planners. It might be further tested and generalized to other streets by counting and computing urban quality factors affecting waking behaviour. This research studied the role of different dimensions of sense of place from the viewpoint of professionals using Delphi method ${ }^{3}$. Further studies are still required to examine other areas and passages. Furthermore, the questionnaire can be used amongst common residents rather than professionals. The method posed in this research can be completed by taking in more local and socio-economic factors into account for different cities and places. Moreover, future researchers may establish more diverse panels for Delphi method in accordance with the objectives of their research.

\section{References}

Adkins, A. (2017). Contextualizing Walkability: Do Relationships Between Built Environments and Walking Vary by Socioeconomic Context?. Journal of the American Planning Association, 83(3), 296-3I4.

Alexander, A. (1977). A Pattern language. Towns, Buildings, Construction. Oxford University Press.

Appleyard, D. (198I). Livable Streets. University of California Press.

Bacon, E. (1967). Design of Cities. Thames \& Hudson.

Banich, M. T. (2004). Cognitive Neuroscience and Neuropsychology. Boston, Houghton Mifflin.

Bently, I. (1985). Responsive Environment: A Manual for Designers. Routledge.

Blowers, A. (1993). Planning for Sustainable Environment, Earthscan.

Bressi, T. W. (1994). Planning the American Dream, in Peter Katz (ed.), The New Urbanism, p. xxvii, McGraw-Hill.

\footnotetext{
${ }^{3}$ The research has been conducted in 2013 .
} 
Buchanan, P. (1988). What City, A Plea for Place in the Public Realm, Architectural Review.

Burton, E Corporation (2004). The Compact City. A Sustainable Urban Form?. Taylor \& Francis.

Calthorpe, P. (1993). The next American Metropolis, Ecology, Community and the American Dream, Princeton Architectural Press.

Carmona, M. (200I). Housing Design Quality: Through Policy, Guidance and Review. London: Routledge.

Carmona, M. (2006). Public Places, Urban Spaces. The Dimensions of Urban Design. Elsevier.

Cooper Marcus, C., Sarkissian, W. (1988). Housing as if People Mattered, Site Design Guidelines for Medium-Density Family Houses. University of California Press.

Coupland, A. (1996). Reclaiming the City, Mixed Use Development. Taylor \& Francis.

Elsheshtawy, Y. (20I3). Dubai Behind an Urban Spectacle. Routledge.

Emadi, A., Yekanifard, A., Rezaei, M. (2014). Sidewalk Building Based on the Sense of Place: A Solution for Creating Sustainable Cities. Journal of Social Issues \& Humanities, 243-250.

Fery, H. (1999). Designing the City: Towards a More Sustainable Urban Form. Taylor \& Francis.

Forsyth, A. (20I5). What is a walkable place? The walkability debate in urban design. Urban Design International, 20, 274-292.

Fulton, W. (1997). New Urbanism. [Online] available at: https://www.lincolninst.edu/sites/default/files/pubfiles/the-new-urbanism-full.pdf [Accessed 30 Dec 2019].

Garreau, J. (1991). Edge City: Life on the New Frontier, Anchor.

Gehl, J. (1987). Life Between Buildings: Using Public Space. Island Press.

Gibberd, F. (1967). Town Design. The Architectural Press, London.

Cullen, G. (196I). Townscape. The Architectural Press, London.

Hough, J. M. (1990). Out of Place: Restoring Identity to the Regional Landscape. Yale University Press.

Jacobs, J. (196I). The Death and Life of Great American Cities. New York: Vintage Books.

Joh, K., Nguyen, M. T., \& Boarnet, M. G. (20I2). Can Built and Social Environmental Factors Encourage Walking among Individuals with Negative Walking Attitudes? Journal of Planning Education and Research, 32(2), 219-236.

Kodukula, S. (20II). Rising Automobile Dependency. Ist ed. Bonn, Germany: Eschborn.

Kopec, D. A. K. (20I2). Environmental Psychology for Design. Fairchild Books.

Lang, J. (1994). Urban Design. The American Experience. John Wally \& Sons.

Lee, L., Buchiner, D. (2008). The Importance of Walking to Public Health. 40(7 Suppl), 5I2-5 I8.

Lynch, K. (1960). The Image of the City. MIT Press.

Lynch, K. (1980). Managing the Sense of a Region. The MIT Press.

Lehman, M., Boyle M. (2007). Healthy \& Walkable Communities, Institute for Public Administration.

Marzbani, M. (20/4). The Role of Historical Fabrics in improvement of Urban Walkability, Unpublished master's thesis supervised by Dr Mahmud Rezaei, Urban Planning Department. Dubai: Islamic Azad University, United Arab Branch.

Melosi, M. V. (2004-20I0). Automobile in American Life and Society The Automobile Shapes The City. [Online] available at: http://www.autolife.umd.umich.edu/Environment/E_Casestudy/E_casestudy I2.htm\#popsu grue [Accessed 26 Dec 2019].

Montgomery, C. (2013). Happy City: Transforming our Lives through Urban Design. Ist ed. New York: Farrar, Straus and Giroux.

Montgomery, J. (1998). Making a City: Urbanity, Vitality and Urban Design. Journal of Urban Design, 3(1), 93-II6.

Nairn, L. (1956). Outrage: On the Disfigurement of Town and Countryside. The Architectural Press, London. 
Newman, O. (1973). Defensible Space: Crime Prevention through Urban Design. MacMillan Publishing.

Pucher J., Dijkstra L. (2003). Promoting Safe Walking and Cycling to Improve Public Health: Lessons from The Netherlands and Germany. AM J Public Health, 93(9), I509-15I6.

Rapoport, A. (1982). The Meaning of the Built Environment: A nonverbal Communication Approach. University of Arizona Press.

Rezaei, M. (20I4). Walkability Criteria: The Role of Walkability in Improving the Sense of Place. Honar-ha-Ziba Memari-va-Shahrsazi, I5-24.

Rogers, R. (1977). Cities for a Small Planet. Faber \& Faber.

Serkal, M. A. (2016). How Dubai plans to turn into walkable city in 4 years. [Online] available at: http://gulfnews.com/news/uae/government/how-dubai-plans-to-turn-into-a-walkable-cityin-4-y.

Shahcheraghi, A. (2015). Environed in Environment. Tehran: Shabak.

Sitte, C. (I889). City Planning According to Artistic Principles.

Speck, J., 2012. Walkable City: How Downtown Can Save America, One Step at a Time. New York: North Point Press. Farrar, Straus and Giroux.

The Happy City (2017). People Not Car. [Online] available at: https://thehappycity.com/wpcontent/uploads/2017/09/17052I_DP202I_FutureXchanges-2017_Full-Report_EN.pdf [Accessed 26 Dec 2019].

Tibbalds, F. (1992). Making People Friendly Towns. Improving the Public Environment in Towns and Cities. Taylor \& Francis.

Unwin, R. (1909). Town Planning in Practice. An Introduction to the Art of Designing Cities and Suburbs.

Whyte, A. V. T. (1977). Field Methods in Guiding for Field Studies in Environmental Perception, Paris: UNESCO.

Whyte, W. (1980). The Social Life of Small Urban Spaces. Conservation Foundation.

Worskett, R. (1969). The Character of Towns. An Approach to conservation. The Architectural Press, London.

Xu, Y. (1995). Definition of Sense of Place, Louis Action.

Yang, Y. (2016). A dynamic framework on travel mode choice focusing on utilitarian walking based on the integration of current knowledge. HHS Public Access. 